\title{
DOE/PC/ $92521-147$
}

TECHNICAL REPORT

March 1, 1993 through May 31, 1993

\section{Project Title: VBF EPR ANALYSIS OF ORGANIC SULFUR IN COAL}

DE-FC22- 92 PC 92521

Principal Investigator: R. B. Clarkson, UIUC

Co-Principal Investigator: R. L. Belford, UIUC Project Manager: Dr. Ken Ho

\section{ABSTRACT}

CEIVL:

SEP 011093

OSTI

One important goal of this project is the development of methods to analyze the Very High Frequency Electron Paramagnetic Resonance (VHF EPR) spectra from Illinois coals in order to determine the concentration of organic sulfur in them. In this third Quarter, the axially symmetric model for the simulation of VHF EPR coal spectra was refined for routine quantitative percent sulfur determination. The computer modeling technique which we have developed makes use of a sophisticated multi-dimensional simplex strategy for optimization. The percent sulfur determined from VHFEPR of sporinite, vitrinite, and two blends of these macerals (from Illinois Herrin No. 6) show excellent linear correlation with far less reliable, time consuming, and difficult techniques.

The method can be extended to calculate the average number of aromatic carbon atoms associated with organic sulfur species. Useful comparisons may be made between the two techniques that promise to provide more information on the relationships between coal structure and coal magnetic resonance spectra. In addition to providing information on the concentration of organic sulfur present in coal, the analysis of VHF EPR spectra also provides detailed spectral parameters which are related to the molecular structure. The nature of these more refined spectral relations continue to be investigated.

US DOE patent clearance IS NOT required to the publication of this document.

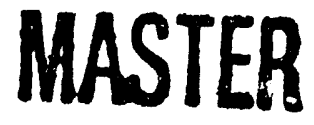

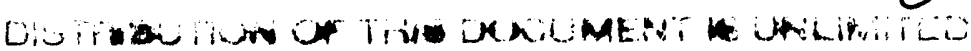


There is a present and growing need for non-destructive methods to analyze coal structure on the molecular level. Future developments in coal processing and utilization require better information concerning patterns of chemical bonding, functional group distribution, and organic heteroatom concentrations and types, to name a few areas of significant need for coal research and engineering. Because coal is an opaque solid with relatively low volatility at room temperature, few analytical techniques can obtain information on its molecular structure in a non-destructive fashion. Because coal structure is sensitive to thermal and chemical modification, the requirements for truly non-destructive methods are stringent, a fact that is especially important when analyzing for the effects of processing or cleaning.

The naturally occurring unpaired electrons in coal have always offered an attractive route to the non-destructive study of coal structure. In a typical Illinois \#6 coal, for example, there are about $10^{19}$ unpaired spins/gram. Because coal is highly aromatic (in this Illinois \#6, ca. $778 \mathrm{C}$, it is estimated that 65 - 708 of the carbon is aromatic, with an average aromatic cluster size of 20 25 carbon atoms [1]), unpaired electrons delocalize over many carbons. Thus, the unpaired electrons in an Illinois \#6 interact directly with $1 \%$ of all the carbon, and $2 \%$ of the aromatic carbon in the coal. This good coverage of the atoms in coal, together with a reasonably uniform distribution of unpaired electrons throughout all maceral components and the exceptional sensitivity of electron paramagnetic resonance (EPR) spectroscopy $\left(10^{3}\right.$ times the sensitivity of ${ }^{1} \mathrm{H}$ NMR) makes the paramagnetic spins very attractive natural observation posts from which to nondestructively analyze coal molecular structure.

The problem that had prevented the EPR approach to coal structure analysis from being more successful was one of resolution. Information about molecular structure and atomic environment was hidden within the EPR spectral lineshape of typical data obtained at $9.5 \mathrm{GHz}$ and $0.34 \mathrm{~T}$. (X-band EPR), and in most cases it could not be deconvolved. This lack of spectral resolution was especialiy maddening in the case of heteroatom $(N, 0, S)$ analysis, where indications of the effects of atomic spin-orbit coupling between the unpaired electrons and heteroatoms were even seen in $X$-band spectra [2], and which higher magnetic field strength experiments were predicted to resolve. In 1990, our laboratory pioneered in the development of a novel $95 \mathrm{GHz}, 3.4 \mathrm{~T}$. (W-band) EPR instrument ${ }^{\dagger}$, and demonstrated that this prediction was correct by examining the suite of Argonne Premium Coal samples, as well as a vitrinite, sporinite, and inertinite maceral separated from an Illinois \#6 coal by density gradient centrifugation [3].

\footnotetext{
'This is the only spectrometer of its kind in the United states, and one of only two in the world.
} 
Chemical evidence strongly suggests that the complex lineshapes seen in the VHF EPR spectra of a coal like IIlinois \#6 (and fusinite and sporinite macerals separated from it) are the result of contributions from several molecular populations, some of which contain sulfur. In order to analyze experimental spectra in a quantitative fashion, we have begun work to create a generalpurpose computer technique, based on the simplex multi-variable optimization strategy, to simulate experimental data in order to obtain spectral parameters ( $g$-values, linewidths, and composition coefficients) which can be correlated to chemical structure. The first tests of this approach have utilized a model of axial symmetry in which all the contributors to the VHF EPR spectrum are grouped into two classes -- sulfur and non-sulfur species -- called the two-species model. Theoretical modeling is based on the very successful QPOW algorithm for powder EPR spectral simulation developed by Belford and co-workers [4]. Graphical results of the application of the technique to VHF EPR spectra from an Illinois \#6 coal and sporinite separated from it are shown in Fig. 1, and Table I summarizes results from several coals.

TABLE I. SUMMARY OF TWO-SPECIES SIMULATION OF FOUR COALS

\begin{tabular}{|c|c|c|c|c|c|c|c|c|c|c|}
\hline Mecend & 8 & $\begin{array}{l}W_{1}(D) \\
\text { (Gausu) }\end{array}$ & $g_{2}(I)$ & $\begin{array}{l}\mathrm{W}_{2}(\mathrm{I}) \\
\text { (Gauss) }\end{array}$ & $8_{1}$ (II) & $\begin{array}{l}\mathrm{W}_{1}(\mathrm{~m}) \\
\text { (Gauso) }\end{array}$ & $B_{2}$ (II) & $\begin{array}{c}w_{2}(\mathrm{Im}) \\
\text { (Gause) }\end{array}$ & $A_{4}$ & $x 3$ \\
\hline Sporinite & 2.00430 & 19.41 & 2.00281 & 8.38 & 2.00301 & 15.74 & 2.00261 & 8.17 & 67 & 4.25 \\
\hline 1:1 (s:V) & 2.00405 & 20.42 & 2.00336 & 10.06 & 2.00308 & 11.73 & 2.00262 & 9.77 & 52 & 3.57 \\
\hline 1:2 (s:V) & 2.00422 & 17.20 & 2.00256 & 6.86 & 2.00312 & 16.84 & 2.00256 & 16.84 & 47 & 3.35 \\
\hline Vitrinite & 2.00399 & 20.36 & 2.00370 & 9.95 & 2.00318 & 12.39 & 2.00257 & 8.45 & 40 & 2.90 \\
\hline
\end{tabular}

The simulation assumes two species, each with axial symmetry $(1=x, y, 2=z)$. $\quad g_{1}$ and $g_{2}$ are the two $g$-values associated with each axiaI species. Numerals I and II in Table I. refer to the two species. $W_{1,2}$ refer to the linewidths of the two components of the spectrum of each species. $A_{I}$ is the normalized integrated intensity of species $I$, which is assumed to contain sulfur. \&S is the literature value for the dry, mineral free content of organic sulfur in each coal as determined by chemical analysis.

In order to better refine and test our methodology, we have investigated a number of maceral blends from Illinois Herrin No. 6 . The VHF-EPR spectra of these blends and their composition are shown in figure 1. Sporinite and vitrinite were separated from Illinois Herrin No. 6 by researchers at Southern Illinois University at Carbondale and their characterization is reported elsewhere. The parameters represented in Table 1 . are the from simplexoptimization simulations of experimental VHF-EPR spectra of four maceral blends.

The $A_{I}$ values correlate with proximate organic sulfur content to better than $\pm 0.5 \%$. They are computed using the equation: 


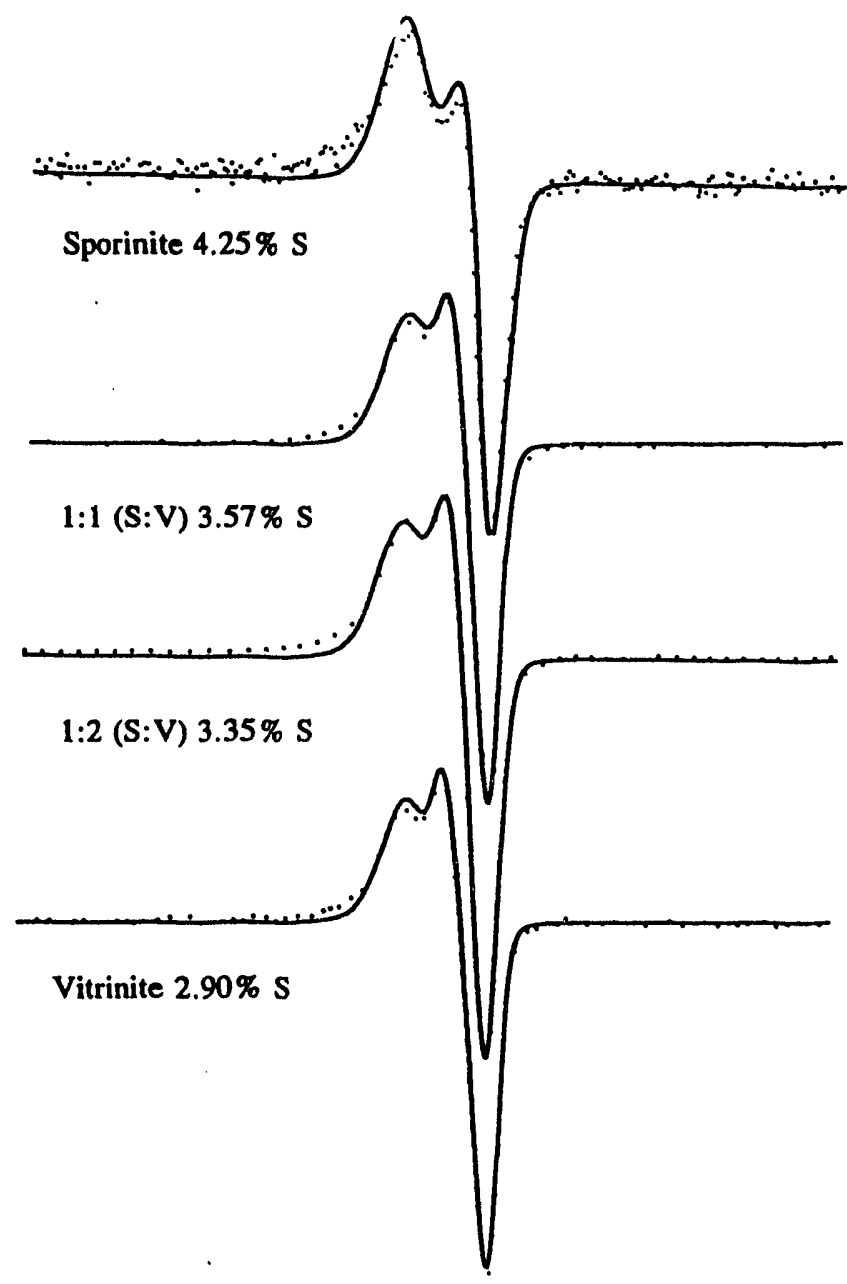

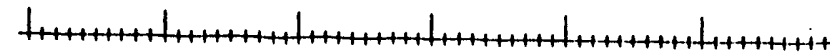
$\begin{array}{llllll}33455 & 33505 & 33555 & 33605 & 33655 & 33705\end{array}$

MGAEIIC FIELO (GALSS)

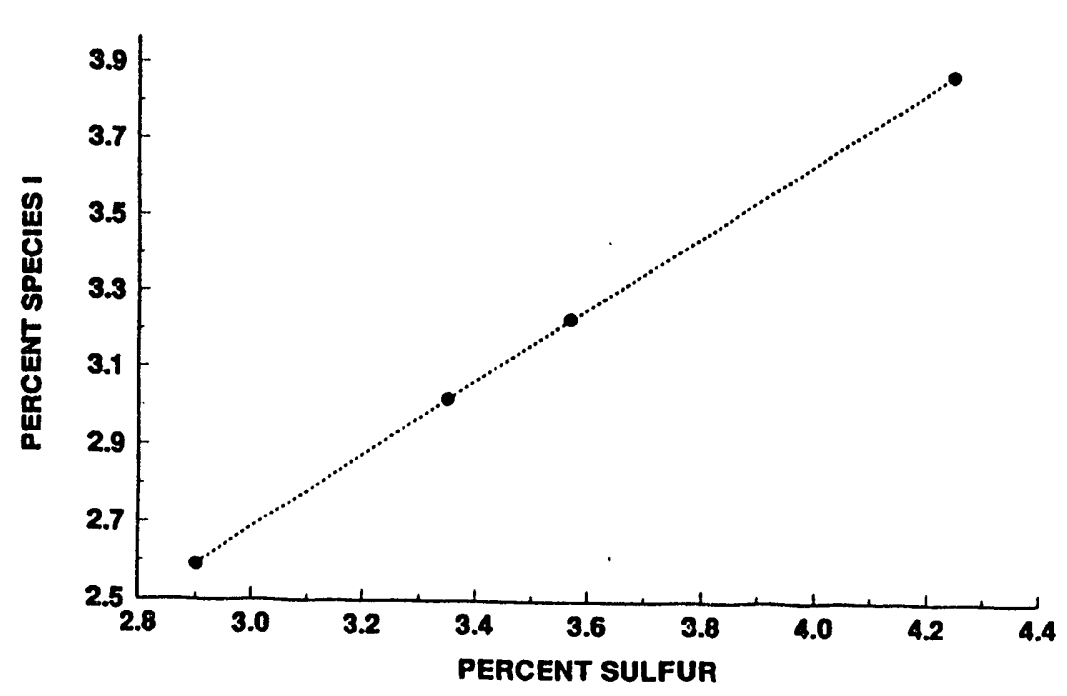

Figure 1. W-band spectra of macerals and maceral blends.

-. Experimental

Simulated; Simplex-optimizea
Figure 2 .

Percent sulfur from our EPR analysis vs. percent sulfur from other methods. 


$$
\frac{(A t \cdot W t . S)}{M_{I}}\left(\frac{A_{I}}{A_{I}+A_{I I}}\right)(C)(1008)=8 s \text { of COaI }
$$

$C$ is the average aromatic fraction of carbon which for the Argonne Premium coals averages about 0.75 , according to NMR data. M is the average molecular weight of the aromatic carbon species (species I) coals which can vary from 250 to greater than 500. Our previous showed that the g-anisotropy in coal is representative of a sixaromatic ring thiophenes containing 22 to 30 carbon atoms. Dianthracene thiophene (M.W. 384) is one such example. Using a slightly larger number of $\mathrm{M}_{\mathrm{I}}=397$ which we previously determined for whole coals, we arrive at $8 S=0.03918 \times A_{1}$. Figure 2 shows the linear correlation of the $8 \mathrm{~S}$ determined from this equation with that determined by other methods. The confidence value is better than 998 .

The development of better computer analysis of VHF EPR spectra as demonstrated in this and the previous quarterly report show that organic sulfur can be determined quickly and non-destructively by this method. Precise analytical "calibration" of the results holds for similar blends of macerals from the same type of coal as well as for very dissimilar coals, so long as they are of about the same rank. Further investigations will study the calibration factor itself as an indicator of the organic structure about the sulfur center as well as rank. A general solution to the analysis that is more rank-independent, and that can utilize a fixed set of spectral parameters to determine organic sulfur species in coal is on the horizon.

1. D. L. Wertz, Am. Chem. Soc. Div. Fuel Chem. Prepr., 36, 1147 (1991).

2. H. L. Retcofsky, in: Coal Science, M. L. Gorbaty, J. W. Larson, and I. Wender, eds.' Academic Press, New York, 1982, Vol. I, Chapter 3, pp. $43-82$.

3. R. B. Clarkson, W. Wang, D. R. Brown, H. C. Crookham, and R. L. Belford, FUEL, 69, 1405 (1990).

4. R. L. Belford, P. H. Davis, G. G. Belford, and T. M. Lenhardt, in Extended Interactions Between Metal Ions in Transition Metal Complexes, L. V. Interrante, ed.; ACS Symposium Series No. 5, American Chemical Society: Washington, 1974; pp $40-50$. 


\section{OBJECTIVES}

Consistent with the three initially proposed phases of the 1992-3 ICCI "VHF EPR Analysis of Organic sulfur in Coal" project, the long term objectives are as follows:

1) Obtain VHF-EPR spectra of coal, solvent extracted coal, and separated macerals. (Phase II)

2) Analyze coal data for organic sulfur structure. (Phase III)

3) Analyze desulfurized coals. (Phase IV)

Research during this third quarter of the 1992-1993 year was highly successful in improving automated analysis using better simulation methods as applied directly to coal and especially coal maceral blend spectra. NMR investigations, and studies of desulfurized coals, are planned for the next quarters. These aspects of this project will continue to dominate our efforts throughout the 1992-93 annual period.

\section{INTRODUCTION AND BACKGROUND}

This program addresses the need for innovative approaches to characterize the organic sulfur in Illinois Basin coals by means of very-high-frequency electron paramagnetic resonance (VHF-EPR) spectroscopy operating at $\mathrm{W}$-band microwave frequencies ( $96 \mathrm{GHz}$ ) . VHF-ERR spectra taken using the unique instrument we have designed and built for such purposes show special sensitivity to heteroatoms in coal. The technique thus can be applied to the problem of nondestructive detection, study, and determination of organic oxygen and sulfur aromatic species in coal. Data from Illinois coals and separated macerals indicate that it is possible to distinguish aromatic from aliphatic sulfur, and may be useful in assessing the extent of conjugation in aromatic portions of the coal. Though XANES/EXAFS and techniques can provide information on sulfur, no single technique should be relied upon entirely, and without other methods of corroboration.

\section{EXPERIMENTAL PROCEDURES}

Simulation of $W$-band EPR Coal spectra

One key goal of this year's work plan is the development of a theoretical model capable of simulating the very high frequency spectra from whole coals and separated macerals. Such a development will allow us to analyze $W$-band spectra in order to better determine how the composition of different coals effects EPR lineshapes. It also may provide more precise information on the 
amount of organic sulfur present in coals, as well as offering the opportunity to model the distribution of molecular forms of sulfur present in the samples.

As a first step in this work, we have modified QPOW, a simulation routine for anisotropic powder EPR spectra, to simulate coal spectra. The "QPOW" computer program is a development of $R$. $I$. Belford, M. J. Nilges, and co-workers in our laboratory. In this implementation of the powder simulation, we have assumed that the coal spectra can be modeled with two species: a sulfur-containing species, called species I, and the remaining, non-sulfur species, called species II. Both molecular forms are assumed to have axial symmetry, with spectra characterized by two $g$-values, $g_{1}$ and $g_{2}$. In this axial model, it is assumed that $g_{A}=g_{B}=g_{1}$, and $g_{c}=g_{2}$.

Associated with each g-value is a spectral lineshape function, characterized by a line width given in Gauss. The lineshapes are assumed to be nearly Gaussian, with a small Lorentzian component (Voigt lineshape), typical for coals. No explicit nuclear hyperfine splitting is included, and the line widths thus are assumed to represent unresolved hyperfine splitting as well as g-value distributions and intrinsic line widths due to relaxation processes.

The $W$-band EPR spectra resulting from two species characterized by such a model thus can be specified by eight spectral parameters (four g-values and four line widths), as well as by one composition variable. In this implementation of the model, the area under species I is allowed to vary, while the area under species II is held constant at an arbitrary value of 100 . The nine independent model parameters then are altered by a "simplex" fitting routine to develop a simulated spectrum that best fits the experimental data. A least squares function is taken as the measure of goodness of fit between theoretical and experimental data.

One important problem which this research is attempting to understand is the relationship between the areas under spectral contributions from species $I$ and II, and the weight percent of organic sulfur in the sample. In order to explore this relationship, we have developed a simple model that makes use of certain properties of EPR spectra. We know, for example, that the area under any EPR spectrum is proportional to the number of paramagnetic centers of that type contributing to the spectrum. Remembering our two-species model, we say:

$$
\begin{aligned}
& \{A(I)\} C=\text { moles of sulfur containing species } I \text { in sample, } \\
& \{A(I I)\} C=\text { moles of non-sulfur species II in sample, }
\end{aligned}
$$

where $A(I)$ and $A$ (II) are the areas under the spectral contributions from species $I$ and II respectively. If $M_{I}$ is the average molecular weight of species $I$, and $M_{I I}$ the average molecular weight of species 
II, then:

(1)

$$
\left(\frac{A_{I} M_{I}}{A_{I} M_{I}+A_{I I} M_{I I}}\right) 1008=\text { Weight8 of Species } I
$$

Of course, we do not know the values of $M_{I, I I}$, but NMR and XANES data suggest that all aromatic forms in coal conform to a rather welldefined distribution of cluster sizes. It is reasonable, therefore, to assume that $\mathrm{M}_{\mathrm{I}}=\mathrm{M}_{\mathrm{II}}$, since we are sure that the radical species we observe in coal are overwhelmingly aromatic in structure. Making this assumption, we now can write that the weight of of sulfur in the aromatic forms in the sample is given by:

$$
\frac{\text { At.Wt.S }}{M_{I}}\left(\frac{A_{I}}{A_{I}+A_{I I}}\right) 1008=\text { wt.8 } S \text { of all aromatics }
$$

There remains only to note that extensive NMR studies of all the Argonne coals show that between 0.7 and 0.8 of all carbon atoms in these coals are aromatic, and the o carbon in each coal usually is a well known number. Then, the overall weight 8 of sulfur in any coal sample is given by:

$$
\frac{(32)(0.7)}{M_{I}}\left(\frac{A_{I}}{A_{I}+A_{I I}}\right)(C)(1008)=85 \text { of } \mathrm{Coal}
$$

where $\mathrm{C}$ is the carbon fraction of the particular sample under investigation, 32 is the atomic weight of sulfur, and 0.75 is the average aromatic fraction of carbon in the Argonne coals.

In the last quarterly report, we showed the results of preliminary simplex VHF-EPR determinations of sulfur in coals with concentrations varying from 2 to $13 \%$ sulfur. The methodology and parameters used for such analysis have been refined and applied to four maceral blends whose VHF-EPR spectra and composition are shown in figure 1. Although the spectra show little individual differentiation to the unaided eye, the "QPOW" simplex simulation program is able to quickly, reliably, repeatedly, and precisely simulate these lineshapes. The least-squares fit is better than 0.99. Parameters ( $g$ tensors and line widths) and species concentrations are generated and are presented in Table 1. 
Using the sulfur species concentration (AI), and the constant $\mathrm{C}=0.03918$

\section{CONCLUSIONS}

Utilizing this improved model, the W-band EPR spectra of four maceral blends have now been analyzed, in addition to the four coal samples presented in the last quarter. Results are given in Table I in the Executive Summary. Using the value of $A_{1}$ for the Illinois \#6 reported in Table $I$ (and remembering that $A_{I I}$ is fixed at 100 in this simulation), we get:

$$
0.0238=9.45 / \mathrm{M}_{\mathrm{I}} \text {. }
$$

The calculation thus predicts that the average molecular weight of the aromatic sulfur species in this coal is $397 \mathrm{~g} / \mathrm{mole}$. Considering a likely molecular structure for these compounds to be the family of polynuclear aromatic thiophenes, this molecular weight corresponds to a six-aromatic-ring thiophene such as dianthracene thiophene (M.W. 384). Our work with model compounds suggested that the g-anisotropy seen in coals could be accounted for by a thiophene containing 22 to 30 carbon atoms. Thus, this two-species model predicts an average molecular form for aromatic sulfur in the Illinois \#6 that is in very close agreement with our predictions, and gives us reason to consider the model adequate for further study. 


\section{Pertinent Recent Publications and Presentations Relating to this Project}

[Note: All of the works cited are of relevance to this project: most but not all were directly supported by this project grant.]

1) W. Wang, R.B. Clarkson, F.P. Auteri, P. Kovacs, M.V. Williamson, and R.I. Belford, "Very High Frequency EPR Spectra of Organic Sulfur Compounds", ACS Div. Fuel Chem. Prepr.. $37(3), 1141$, 1992.

2) W. Wang, R.B. Clarkson, F.P. Auteri, P. Kovacs, M.V. Williamson, and R.L. Belford, "Very High Frequency EPR Spectra of Organic Sulfur Compounds", presented at the "Symposium on Analytical Techniques for Characterizing Coal and Coal Conversion Products", 204th ACS National Meeting, Washington D.C., Aug. 25th, 1992.

3) R.B. Clarkson, W. Wang, F.P. Auteri, P. Kovacs, and R.I. Belford, "VHF-EPR of High Sulfur Coal and Heterocyclic Radicals", presented at the "34th Rocky Mountain Conference on Analytical Chemistry and Applied Spectroscopy", Denver, August 4th, 1992.

4) R.B. Clarkson, F. Auteri, S. Boyer, T. Smirnov, N. Vahidi, and R.I. Belford, "Influence of Paramagnetic Gases on EPR Iinewidths of Carbon Chars", presented at "VI International Symposium on Magnetic Reson. in Colloid and Interface Science", Florence, Italy, June 1992 .

6) H.M. Swartz, S. Boyer, P. Gast, J.F. Glockner, H. Hu, K.J. Liu, M. Moussavi, S.W. Norby, N. Vahidi, T. Walczak, M. Wu, and R.B. Clarkson, "Measurements of Pertinent Concentrations of Oxygen in Vivo", Magn. Resonance in Med. 20, 333-339, 1991.

7) R.B. Clarkson, K. Motsegood, W. Wang, A.G. Webb, and R.L. Belford, "Very High Frequency EPR Spectroscopy and NMR Imaging of Coal," Am. Chem. Soc. Preprints Fuel Chem., 36, 1283, 1991.

8) R.B. Clarkson, S. Boyer, M.J. Nilges, W. Wang, and R.L. Belford, "Multidimensional EMR of American Coals," in Coal Science Proceedings, Butterworth/Heinemann, Oxford, 1991, 68-71.

9) R.B. Clarkson, D. R. Brown, H. C. Crookham, J. B. Cornelius, W.J. Shi, and R. L. Belford, "S-Band Electron Spin Echo Spectroscopy", J. Pure Appl. Chem., 64, 893, 1992.

10) R.B. Clarkson, W. Wang, D.R. Brown, H.C. Crookham, and R.L. Belford, "Electron Magnetic Resonance of Standard Coal Samples at Multiple Microwave Frequencies," in Magnetic Resonance of Carbonaceous Solids, R. Botto and Y. Sanada, eds.. ACS Advances in Chemistry Series, American Chemical Society, Washington, 229, 507, 
1993.

11) R. L. Belford and R. B. Clarkson, "Multi-Frequency Electron Magnetic Resonance Spectroscopy," in Magnetic Resonance of Carbonaceous Solids, R. Botto and Y. Sanada, eds., ACS Advances in Chemistry Series, American Chemical Society, Washington, 229, 107, 1992 .

12) R. B. Clarkson, W. Wang, M. J. Nilges, and R. L. Belford, "Multi-Dimensional EMR of American Coals," 2d International Conference on Coal structure, Newcastle, 1991.

13) Shong-Wan Norby, A. I. Smirnov, H. M. Swartz, and R. B. Clarkson, "Application of Porous Synthetic Chars for measurement of Concentration of Oxygen by EPR In Vivo," ACS Colloid and Surface Science Symposium, Morgantown, 1992.

14) Shong-Wan Norby, A. I. Smirnov, S. J. Boyer, and R. B. Clarkson, "Surface Structure and EPR Properties of Oxygen Sensitive EPR Probes," ACS Colloid and Surface Science Symposium, Morgantown, 1992 .

15) T. I. Smirnov, R. L. Belford, and R. B. Clarkson, Magnetic Properties of Coal and Char Materials Measured by EPR and SQUID Techniques," ACS Colloid and Surface Science Symposium, Morgantown, 1992 .

16) R. B. Clarkson, A. G. Webb, F. Auteri, and K. Motsegood, "MRI Studies of Coal and Porous Solids," ACS Colloid and Interface Science Symposium, Morgantown, 1992. 
PROJECT MANAGEMENT REPORT

March 1, 1993 through May 31, 1993

Project Title: VHF EPR ANALYSIS OF ORGANIC SULFUR IN COAL

Principal Investigator: R. B. Clarkson, UIUC

Co-Principal Investigator: R. L. Belford, UIUC

Project Manager: Dr. Ken Ho

COMMENTS

The budget for the third quarter is on schedule. 


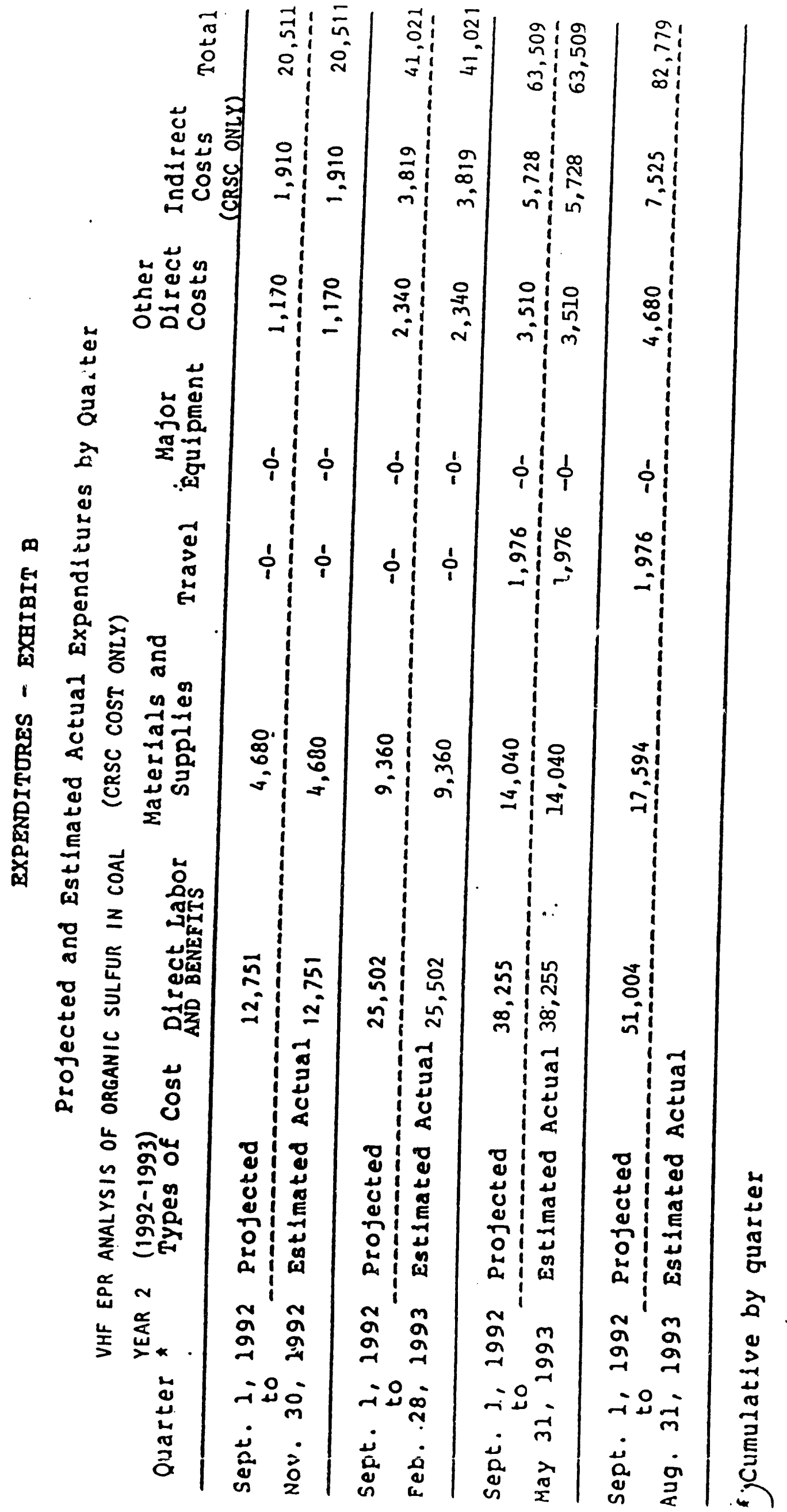


COSTS BY QUARTER - EXHIBIT C

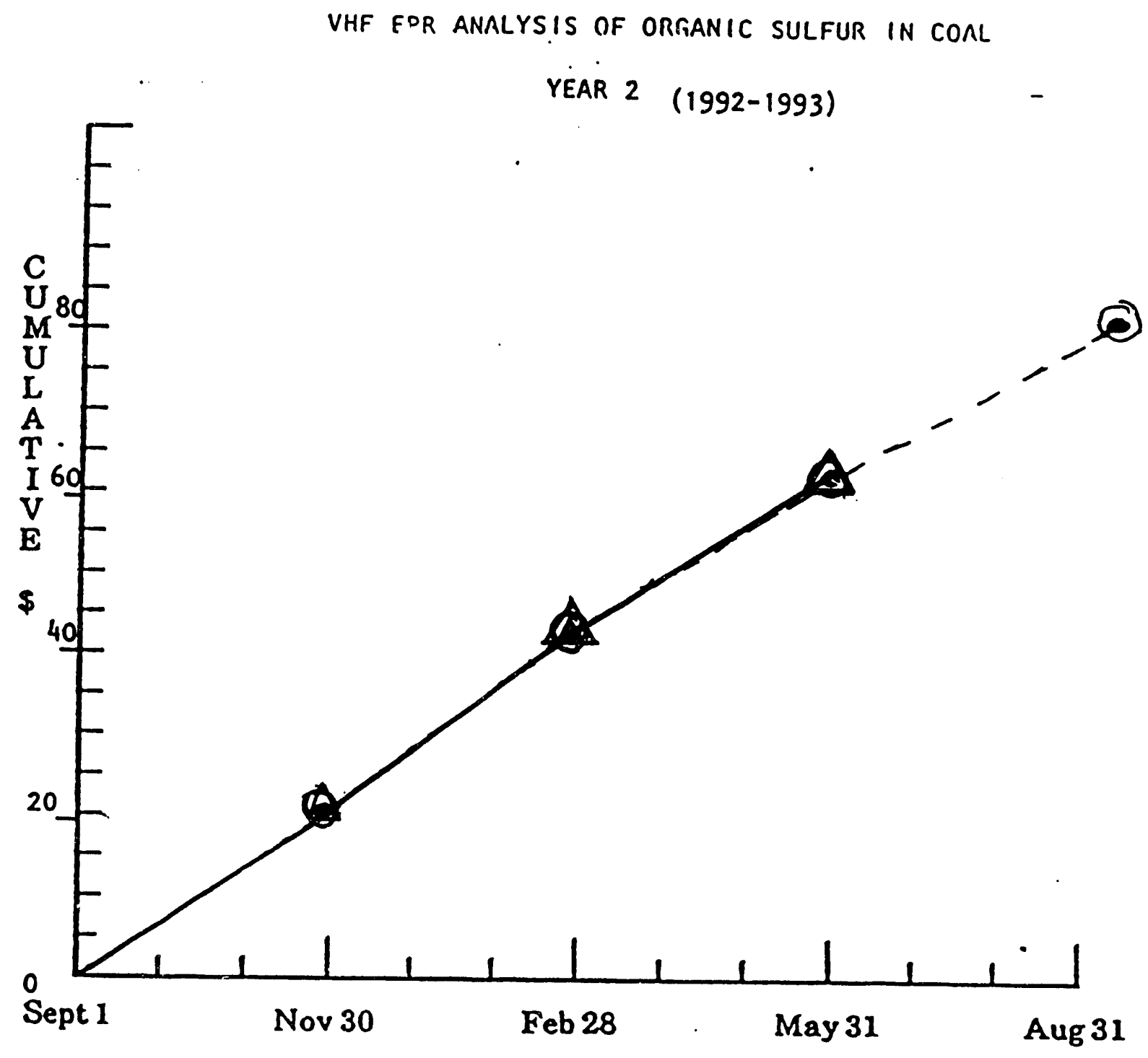

Months and Quarters

$0=$ Projected Expenditures

$\Delta=$ Actual Expenditures

Total CRSC Award $\$ 82,779$ 
VHF EFR ANALYSIS OF ORGANIC SULFUR IN COAL SCHEDULE OF PROJECT MILESTONES

YEAR 2 (1992-1993)

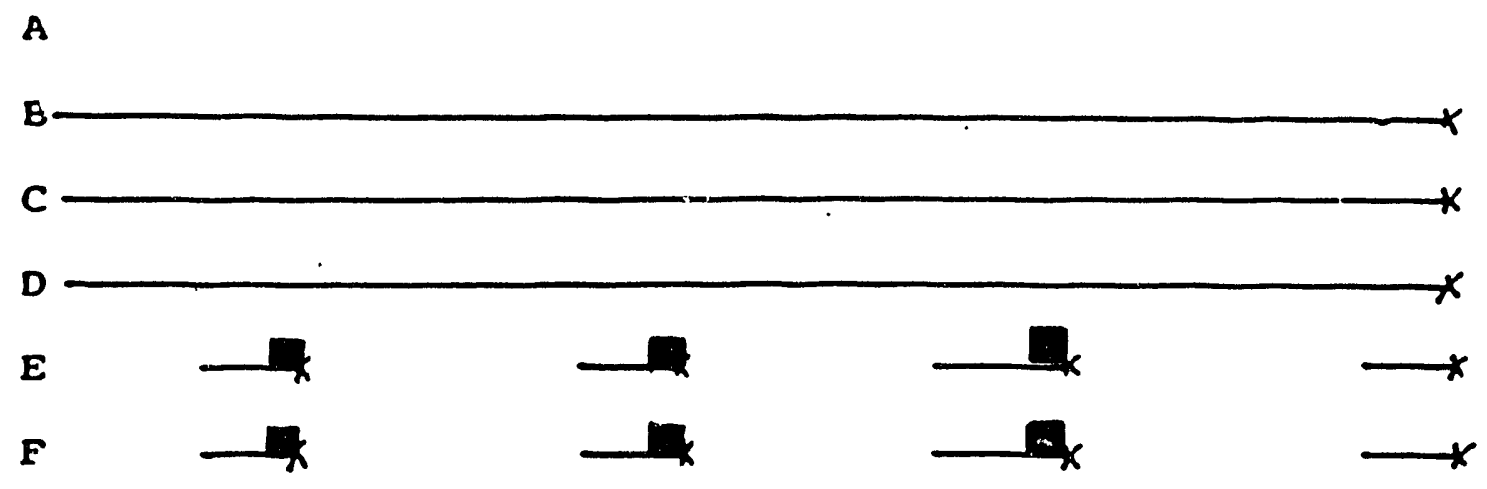

$\begin{array}{llllllllllllll}\text { Begin } & S & 0 & N & D & J & F & M & A & M & J & J & A\end{array}$.

Sept 1

1992

A. PHASE 1

B. PHASE II

C. PHASE III

D. PHASE IV

E. SCIENTIFIC PROGRESS REPORT.

F. PROJECT MANAGEMENT REPORT 

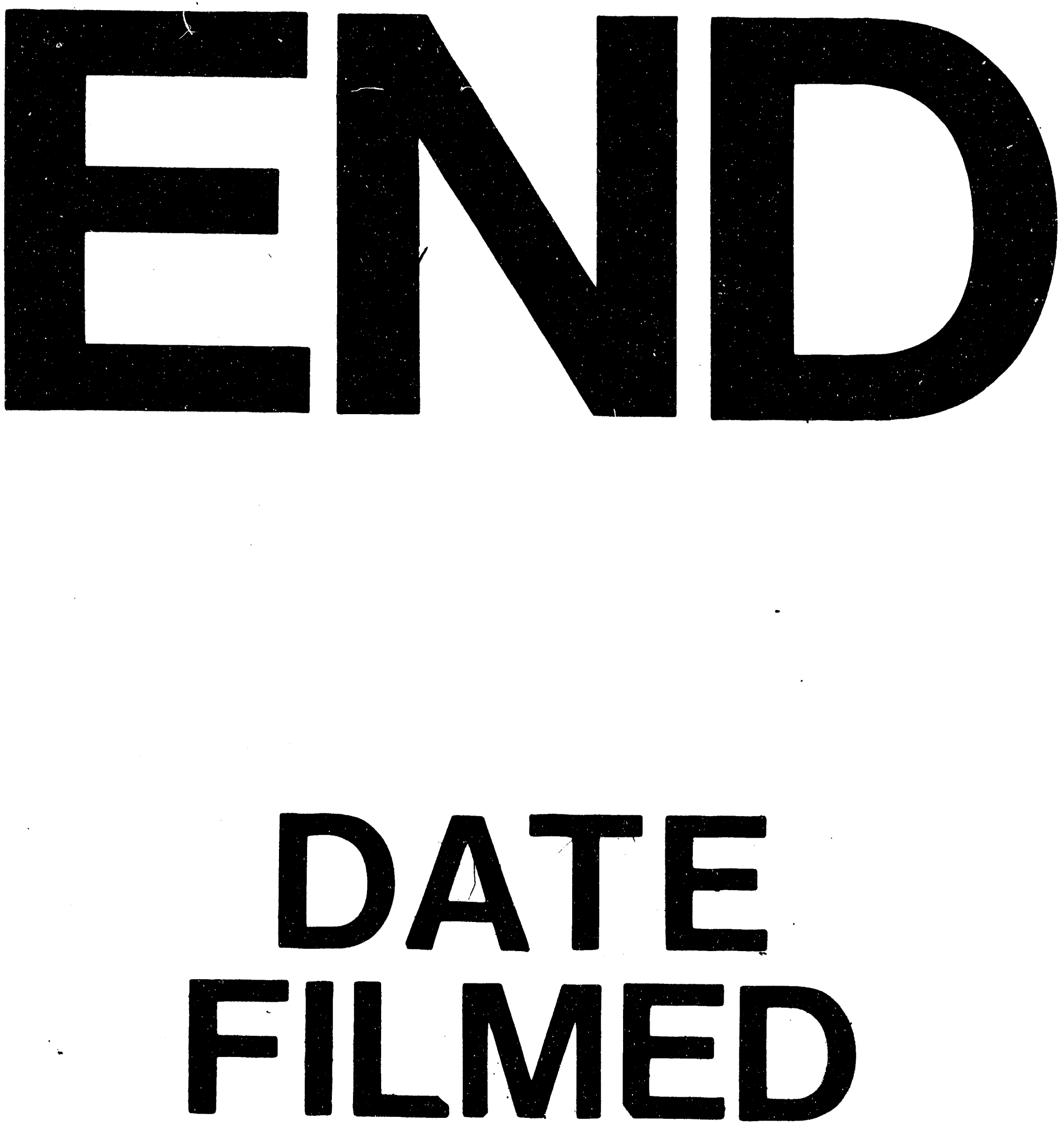

1

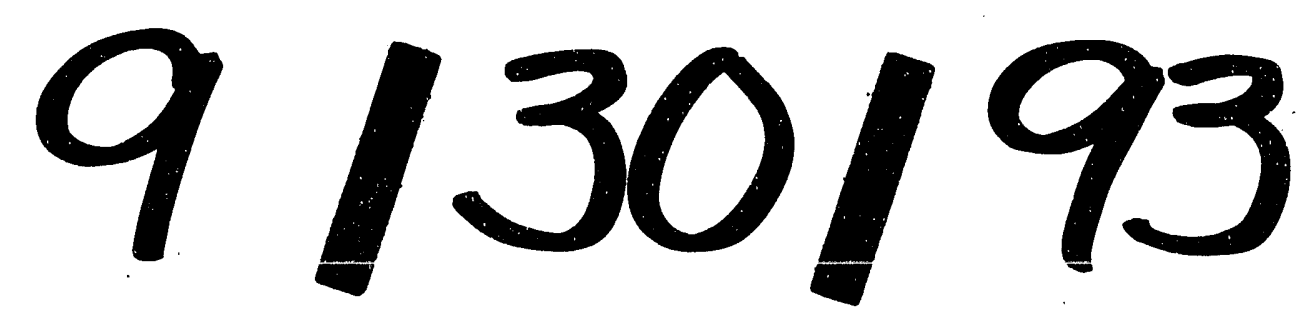


